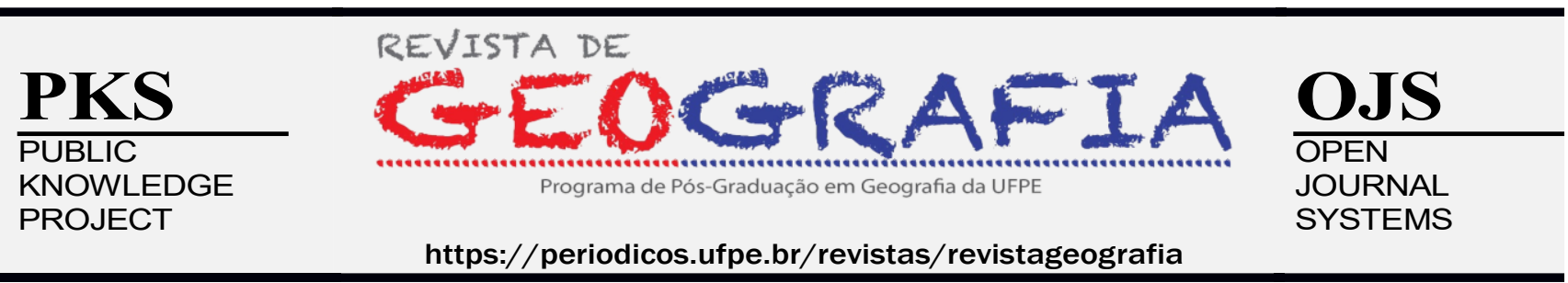

\title{
FRAGILIDADE AMBIENTAL DA PENÍNSULA DE MARAÚ - BAHIA
}

\author{
Elizabeth Santos de Oliveira ${ }^{1}$, Ana Maria Souza dos Santos Moreau ${ }^{2}$
}

\begin{abstract}
${ }^{1}$ Universidade Estadual de Santa Cruz.E-mail: olivrelizabeth@outlook.com http://orcid.org/0000-0001-8589-7977
${ }^{2}$ Universidade Estadual de Santa Cruz.E-mail: amoreau@uesc.br http://orcid.org/0000-0003-3909-2734
\end{abstract}

Artigo recebido em 17/06/2021 e aceito em 04/10/2021

\begin{abstract}
RESUMO
O presente estudo tem como proposta mapear a fragilidade natural e ambiental da Península de Maraú (Bahia), realizando uma abordagem dos fatores que influenciam na vulnerabilidade desse ambiente. Para tanto, adotouse a metodologia de análise de multicritério que é baseada na combinação de diferentes variáveis para gerar o mapa de fragilidade ambiental, para isso são atribuídos pesos e notas para cada variável (atributo) e suas respectivas classes de acordo com a sua influência no ambiente estudado. Todos os procedimentos para a elaboração dos mapas foram realizados em ambiente SIG (Sistema de Informações Geográficas) com a utilização dos softwares QGis 3.10 e 2.8.9. Os resultados obtidos apontam que a Península de Maraú possui muito alta fragilidade natural em $76 \%$ da área estudada e média em $23 \%$, já os resultados para a fragilidade ambiental (para o ano de 2020) apontaram que $47 \%$ da área estudada é classificada como de alta fragilidade e $30 \%$ como média. De modo geral, os atributos solos e substratos rochosos são os principais influenciadores da alta fragilidade natural da área estudada, principalmente nos locais com predominância de substratos arenosos, sedimentos e manguezais, pois são mais susceptíveis à erosão. Entretanto, a cobertura vegetal das restingas, florestas e manguezais atuam como amenizadores dos processos erosivos, como demonstrou o mapa de fragilidade ambiental. Em áreas com cobertura vegetal preservada (restingas, florestas/SAF e manguezais) houve a diminuição da classe de fragilidade muito alta, essa classificação demonstrou-se apenas nas tipologias alagados ou povoados/solo descoberto.
\end{abstract}

Palavras-chave: análise de multicritério; uso e ocupação do solo; zona costeira; análise ambiental.

\section{ENVIRONMENTAL FRAGILITY OF THE MARAÚ PENINSULA - BAHIA}

\section{ABSTRACT}

The present study aims to map the natural and environmental fragility of the Maraú Peninsula (Bahia), addressing the factors that influence the vulnerability of this environment. For that, the multicriteria analysis methodology was adopted, which is based on the combination of different variables to generate the environmental fragility map. For this, weights and grades are assigned to each variable (attribute) and their 
respective classes according to their influence on the studied environment. All procedures for preparing the maps were performed in a GIS environment (Geographic Information System) using the QGis 3.10 and 2.8.9 software. The results obtained show that the Maraú Peninsula has a very high natural fragility in $76 \%$ of the studied area and an average natural fragility in $23 \%$, whereas the results for environmental fragility (for the year 2020) pointed out that $47 \%$ of the studied area it is classified as highly fragile and $30 \%$ as medium. In general, the attributes soil and rocky substrates are the main influencers of the high natural fragility of the studied area, mainly in places with a predominance of sandy substrates, sediments and mangroves, as they are more susceptible to erosion. However, the vegetation cover of restinga (coast forest), forests and mangroves act as a mitigation of the erosive processes, as demonstrated by the environmental fragility map. In areas with preserved vegetation cover (restingas, forests/AFS and mangroves) there was a decrease in the class of very high fragility, this classification was demonstrated only in Marshes or Settlements / Uncovered Soil types.

Keywords: multicriteria analysis; land use and occupation; coastal zone; environmental analysis.

\section{INTRODUÇÃO}

As transformações da sociedade nas últimas décadas causaram também importantes modificações ao meio físico, evidenciando a importância em debater e analisar os impactos ocasionados por ações antrópicas ao ambiente. Principalmente as transformações do uso e ocupação da terra que podem comprometer recursos naturais importantes para a manutenção da biodiversidade, como a cobertura vegetal, recursos hídricos, e o solo. Nesse sentido, foram realizados diversos trabalhos com objetivo de estabelecer métodos para o estudo da fragilidade, vulnerabilidade, ou ainda, sensibilidade ambiental, que tiveram como produto final importantes ferramentas de zoneamento ambiental (ROSS, 1994; CEPRANI et al., 1996; GRIGIO, 2003; TAGLIANI, 2003; LIMA \& AMARAL, 2013).

Neste trabalho, adotou-se que a vulnerabilidade natural (fragilidade natural) é produzida através das características físicas do ambiente (GRIGIO, 2003, 2004, 2008), enquanto que a vulnerabilidade ambiental (fragilidade ambiental) está relacionada com a maior ou menor susceptibilidade de um ambiente a um impacto potencial provocado por um uso antrópico qualquer, sendo que susceptível refere-se a tendência de um ambiente adquirir novas características e, assim, causar desequilíbrio ao sistema (TAGLIANI, 2003).

Os estudos da fragilidade natural e ambiental são importantes instrumentos de gestão que possibilitam o zoneamento, monitoramento e tomadas de decisões em ecossistemas costeiros (WALDBURGER, 2014). A alta complexidade ambiental de regiões litorâneas é um fator agravante em relação a necessidade de planejamento urbano, pois quando não realizado pode ocasionar graves consequências ao ambiente físico, bem como para populações residentes em áreas ocupadas desordenadamente, ou até mesmo em ambientes naturalmente frágeis (BENAVIDES SILVA; MACHADO, 2014). Nesse contexto, o presente estudo tem como proposta mapear a fragilidade 
natural e ambiental da APA da Península de Maraú (Bahia), abordando fatores que influenciam na vulnerabilidade desse ambiente.

\section{MÉTODO ADOTADO}

Esta pesquisa foi desenvolvida a partir de três etapas, sendo elas:

Etapa 1 - Pesquisa na literatura referente à caracterização da área de estudo, no caso foram utilizados dados do município de Maraú, e sobre metodologias e técnicas aplicadas no mapeamento de fragilidade ambiental.

Etapa 2 - Coleta de informações para a criação da base de dados espaciais, tratamento das bases já existentes, e elaboração de mapas temáticos.

Etapa 3 - Elaboração dos mapas de fragilidade natural e ambiental a partir da metodologia de análise de multicritério, e posterior análise dos resultados encontrados.

A base cartográfica utilizada foi elaborada a partir dos dados digitais em formato de shapefile na escala 1:100.000, foram utilizadas as folhas Ituberá (2055), Ubaitaba (2099) e Velha Boipeba (2056), provenientes da cobertura plani-altimétrica da SEI. As informações específicas da Península de Maraú foram adquiridas a partir do trabalho realizado por Waldburguer (2014), foram utilizados os mapas de caracterização do substrato rochoso, solo e unidades geoambientais.

Os dados com informações altimétricas foram adquiridos através do sensor Alos Palsar da plataforma Alaska Satellite Facility (ASF, 2020), que possui resolução espacial de 12,5 metros, as imagens AP_26664_FBS_F6900_RT1 e AP_26912_FBS_F6900_RT1, abrangem todo o munícipio estudado. A imagens foram submetidas ao pré-processamento no ambiente SIG do software QGis 3.10.5 com associação da extensão do GRASS, que seguiram os procedimentos: geração do mosaico, reprojeção do raster e substituição dos pixels negativos, o último foi realizado através da ferramenta Raster Calculator do SAGA e aplicação da fórmula "iFELSE $(a<0,1, a)$ ”. Após o pré-processamento, com as ferramentas Declividade e r.reclass obteve-se o mapa de declividade.

O mapa de Índice de Vegetação por Diferença Normalizada (NDVI - Normalized Difference Vegetation Index), foi adquirido na plataforma Google Earth Engine (GEE, 2020) a partir de um conjunto de imagens do satélite LandSat 8 - OLI. Inicialmente foi aplicado o filtro de data para o período 2014-2019 e o filtro de porcentagem de nuvens para gerar o mosaico temporal, todos esses 
processos foram realizados no GEE (Google Earth Engine) a partir de scripts pré-definidos, que detêm de informações e parâmetros necessários para gerar o dado final. Para obter o NDVI foi gerada a variável função "var ndvi = image.expression('(nir-red)/(nir+red)')" a partir das bandas espectrais B4 (red) e B5 (nir) do mosaico temporal.

O mapa de uso e ocupação do solo foi elaborado em ambiente SIG utilizando o software QGis 3.10.5 com associação da extensão do GRASS, para a manipulação da imagem LO82150702020204CUB00 do satélite LandSat 8LC (sensores OLI e TIRS - Operational Land Imager e Thermal Infrared Sensor, respectivamente), datada de 22/07/2020, disponível gratuitamente no banco de dados do Instituto Nacional de Pesquisa Espaciais (INPE, 2020).

A imagem foi submetida ao pré-processamento (Preprocessing), para reprojeção do sistema de referência de coordenadas e correção atmosférica, que foi realizada a partir do modelo Dark Object Subtraction (DOS), através do Semi-Automatic Classification Plugin (SCP). Foi utilizado o mesmo plugnin SCP para gerar a composição (virtual raster) e posteriormente a composição falsa cor RGB543.

Adotou-se o método de classificação supervisionada a partir da retirada de amostras espectrais da imagem, e posteriormente utilizou-se o algoritmo Máxima Verossimilhança (MaxVer) para o mapeamento das classes: Superfície Aquática, Alagados, Manguezais, Apicuns, Restinga, Campos de Restinga, Floresta/SAF (Sistema Agroflorestal), Agricultura/Pastagem e Povoados/Solo Descoberto. O mapeamento obtido foi submetido ao refinamento da imagem, para isso utilizou-se a ferramenta Classification sieve, que está presente no plugin SCP e tem a função de remover pixels isolados.

É importante ressaltar que as classes selecionadas para a aplicação da metodologia foram baseadas no estudo Waldburguer e Gomes (2016) e no Zoneamento Ambiental da APA da Península de Maraú (BAHIATURSA, 2000). A validação geral do mapeamento foi realizada com a utilização da ferramenta de pós-processamento Accuracy do plugin SCP, bem como a validação a partir da visita de campo.

\section{Mapeamento da Fragilidade Ambiental}

No ambiente SIG do QGis 2.8.9 foi elaborado o mapa de fragilidade ambiental utilizando a análise de multicritério, que permite a investigação combinada de diferentes variáveis, tendo em vista 
que a vulnerabilidade ambiental de uma área depende da relação entre uma série de variáveis condicionantes (BENAVIDES SILVA; MACHADO, 2014).

Moura (2007, p. 2901) descreveu a análise de multicritério como:

[...] um procedimento metodológico de cruzamento de variáveis amplamente aceito nas análises espaciais. Ela é também conhecida como Árvore de Decisões ou como Análise Hierárquica de Pesos. O procedimento baseia-se no mapeamento de variáveis por plano de informação e na definição do grau de pertinência de cada plano de informação e de cada um de seus componentes de legenda para a construção do resultado final. A matemática empregada é a simples Média Ponderada, mas há pesquisadores que já utilizam a lógica Fuzzy para atribuir os pesos e notas.

Considerando essa metodologia foram atribuídos pesos $(0$ - 100\%) para cada variável global da fragilidade natural (substrato rochoso, solos, declividade e clima) e fragilidade ambiental (substrato rochoso, solos, declividade, clima, uso e ocupação do solo e vigor da vegetação). A determinação da hierarquia das variáveis globais foi realizada através da calculadora AHP (Análise Hierárquica de Pesos), método desenvolvido pelo Prof. Thomas Saaty em 1978, na Universidade da Pensilvânia, e tem a função de auxiliar na atribuição dos pesos para cada plano de informação. Nesse método o especialista define o grau de importância de cada variável global para a composição utilizando a escala numérica de Saaty apresentada na Tabela 1 (MOURA, 2007).

Foi utilizada a calculadora AHP online (AHP-OS, 2020) para ponderar sobre o grau de importância das variáveis globais para o estudo da fragilidade natural e ambiental da Península de Maraú. A hierarquia das variáveis globais e os pesos de suas componentes legendadas (subcritério de cada variável global) estão descritos na Tabela 2. É importante ressaltar que a atribuição do grau de importância das variáveis globais e os pesos dos subcritérios foram adaptados de acordo aos trabalhos dos autores Waldburguer e Gomes (2016) e Benavides Silva e Machado (2014). Optou-se por realizar alterações nas variáveis utilizadas para gerar o mapa de fragilidade ambiental, por isso foram utilizadas variáveis globais de caracterização física (substrato rochoso, solos, declividade e clima) e variáveis globais que representam a influência antrópica na área de estudada (uso e ocupação do solo e vigor de vegetação).

Utilizou-se o NDVI para complementar os dados relativos ao uso e ocupação do solo, tendo em vista as limitações dessas variáveis quando utilizadas separadamente. O mapa de uso e ocupação do solo apresenta limitações quanto aos erros ocasionados em áreas de transição entre classes devido à resolução da imagem LandSat ( 30 x 30 metros), enquanto que o NDVI é eficiente em distinguir classes de solo com cobertura vegetal 
e solo exposto, mas não faz distinção entre os tipos de vegetação e uso do solo (DERMACHI et al. 2011). Em razão disso foram utilizadas essas duas variáveis para gerar o mapa de fragilidade ambiental.

Tabela 1 - Escala numérica de Saaty.

\begin{tabular}{|c|c|c|}
\hline Escala Numérica & Escala Verbal & Explicação \\
\hline 1 & $\begin{array}{l}\text { Ambos os elementos são de igual } \\
\text { importância }\end{array}$ & $\begin{array}{l}\text { Ambos os elementos contribuem com a propriedade de } \\
\text { igual forma }\end{array}$ \\
\hline 3 & $\begin{array}{l}\text { Moderada importância de um } \\
\text { elemento sobre outro }\end{array}$ & $\begin{array}{l}\text { A experiência e a opinião favorecem um elemento sobre o } \\
\text { outro }\end{array}$ \\
\hline 5 & $\begin{array}{l}\text { Forte importância de um elemento } \\
\text { sobre o outro }\end{array}$ & Um elemento é fortemente favorecido \\
\hline 7 & $\begin{array}{l}\text { Importância muito forte de um } \\
\text { elemento sobre o outro }\end{array}$ & Um elemento é muito fortemente favorecido sobre o outro \\
\hline 9 & $\begin{array}{l}\text { Extrema importância de um } \\
\text { elemento sobre o outro }\end{array}$ & $\begin{array}{l}\text { Um elemento é favorecido pelo menos com uma ordem de } \\
\text { magnitude de diferença }\end{array}$ \\
\hline $2,4,6,8$ & $\begin{array}{l}\text { Valores intermediários entre } \\
\text { opiniões adjacentes }\end{array}$ & Usado como valores de consenso entre opiniões \\
\hline Incremento 0,1 & $\begin{array}{l}\text { Valores intermediários na graduação } \\
\text { mais fina de } 0,1\end{array}$ & Usados para graduações mais finas das opiniões \\
\hline
\end{tabular}

Fonte: Roche \& Vejo (2004 apud Morimoto \& Oliveira, 2019).

Para aplicar a metodologia AHP e gerar os mapas de fragilidade natural e ambiental foram utilizados recursos disponíveis no Sistema de Informação Geográfica (SIG), mais especificamente os softwares QGis 3.10 e 2.8.9 com a extensão Easy AHP plugin. O raster de cada variável (substrato rochoso, declividade, clima, solos, vigor de vegetação, uso e ocupação do solo) foi reclassificado com o auxílio das ferramentas r.reclass e r.recode. Esse processo deve ser realizado para a normalização das variáveis globais, por isso cada subcritério (componentes da legenda) variam de 1 à 5 (Tabela 2), de maneira que quanto maior a nota, maior a susceptibilidade erosiva (1: muito baixa; 2: baixa; 3: média; 4: alta; 5: muito alta). Posteriormente as variáveis globais reclassificadas foram utilizadas como dado de entrada ao Easy AHP plugin, este, por sua vez, utilizou as informações dos pesos da AHP (Tabela 2) em formato matricial e aplicou o método de Combinação Linear Ponderada (VOOGD, 1983) para gerar os mapas de fragilidade natural e ambiental.

Tabela 2 - Valores de fragilidade para os atributos avaliados na área em estudo.

\begin{tabular}{|c|c|c|c|}
\hline Atributos & $\begin{array}{c}\text { Pesos dos Componentes das } \\
\text { Legendas }\end{array}$ & $\begin{array}{c}\text { Fragilidade Ambiental } \\
\text { Natural } \\
\text { Pesos AHP }(0-100 \%)\end{array}$ & $\begin{array}{c}\text { Fragilidade Ambiental com } \\
\text { Influência Antrópica } \\
\text { Pesos AHP (0-100\%) }\end{array}$ \\
\hline Substrato Rochoso & & 32,60 & 8,70 \\
\hline Pântanos e Mangues Atuais & 5,0 & & \\
\hline Embasamento Cristalino & 2,0 & & \\
\hline Areias Litorâneas & 5,0 & & \\
\hline Grupo Barreiras & 3,0 & & \\
\hline Formação Algodões & 4,0 & & \\
\hline Formação Taipus-Mirim & 3,0 & & \\
\hline
\end{tabular}




\begin{tabular}{|c|c|c|c|}
\hline Terraços Marinhos & 5,0 & & \\
\hline Dépositos de leques Aluvionares & 5,0 & & \\
\hline Dépositos Flúvio-Lagunares & 5,0 & & \\
\hline Classes de Declividade (\%) & & 7,60 & 4,30 \\
\hline$<6$ & 1,0 & & \\
\hline $6-12$ & 2,0 & & \\
\hline $12-20$ & 3,0 & & \\
\hline $20-30$ & 4,0 & & \\
\hline$>30$ & 5,0 & & \\
\hline Clima & 3,0 & 4,80 & 2,50 \\
\hline Solos & & 54,90 & 18,90 \\
\hline Gleissolos & 5,0 & & \\
\hline Neossolos Quartzarênicos & 5,0 & & \\
\hline Argissolos V.A. distróficos & 1,0 & & \\
\hline Argissolos V.A. eutróficos & 1,0 & & \\
\hline Latossolos Amarelos distróficos & 2,0 & & \\
\hline Espodossolo Hidromórfico & 5,0 & & \\
\hline Latossolo Vermelho-Amarelo Distrófico & 2,0 & & \\
\hline Vigor de Vegetação (NDVI) & & 34,30 & 21,70 \\
\hline $1-0,4902$ & 1,0 & & \\
\hline $0,4902-0,3412$ & 2,0 & & \\
\hline $0,3412-0,2157$ & 3,0 & & \\
\hline $0,2157-0,0667$ & 4,0 & & \\
\hline $0,0667--1,0000$ & 5,0 & & \\
\hline Uso e Ocupação do Solo & & & 44,00 \\
\hline Superfície Aquática & 1,0 & & \\
\hline Manguezais & 1,0 & & \\
\hline Apicuns & 3,0 & & \\
\hline Restinga & 3,0 & & \\
\hline Campos de Restinga & 3,0 & & \\
\hline Alagados & 5,0 & & \\
\hline Floresta/SAF & 1,0 & & \\
\hline Agricultura/Pastagem & 3,0 & & \\
\hline Povoados / Solo Descoberto & 5,0 & & \\
\hline
\end{tabular}

Fonte: Adaptado de Waldburguer e Gomes (2016) e Benavides Silva e Machado (2014).

\section{CARACTERIZAÇÃO DA PENÍNSULA DE MARAÚ}

A área estudada (figura 1) está localizada no município de Maraú na região litoral sul do estado da Bahia, e seu território compõe a APA (Área de Proteção Ambiental) da Península de Maraú. O clima do município é quente e úmido e sem estação de seca, típico de clima tropical costeiro, classificado como Af por Köppen (1936). Segundo a classificação climática do Climate-data (2021), Maraú está a $5 \mathrm{~m}$ do nível do mar e apresenta clima tropical, a temperatura média é de $24.7^{\circ} \mathrm{C}$ e a pluviosidade média anual de $2327 \mathrm{~mm}$. 
Figura 1 - Localização da área em estudo.

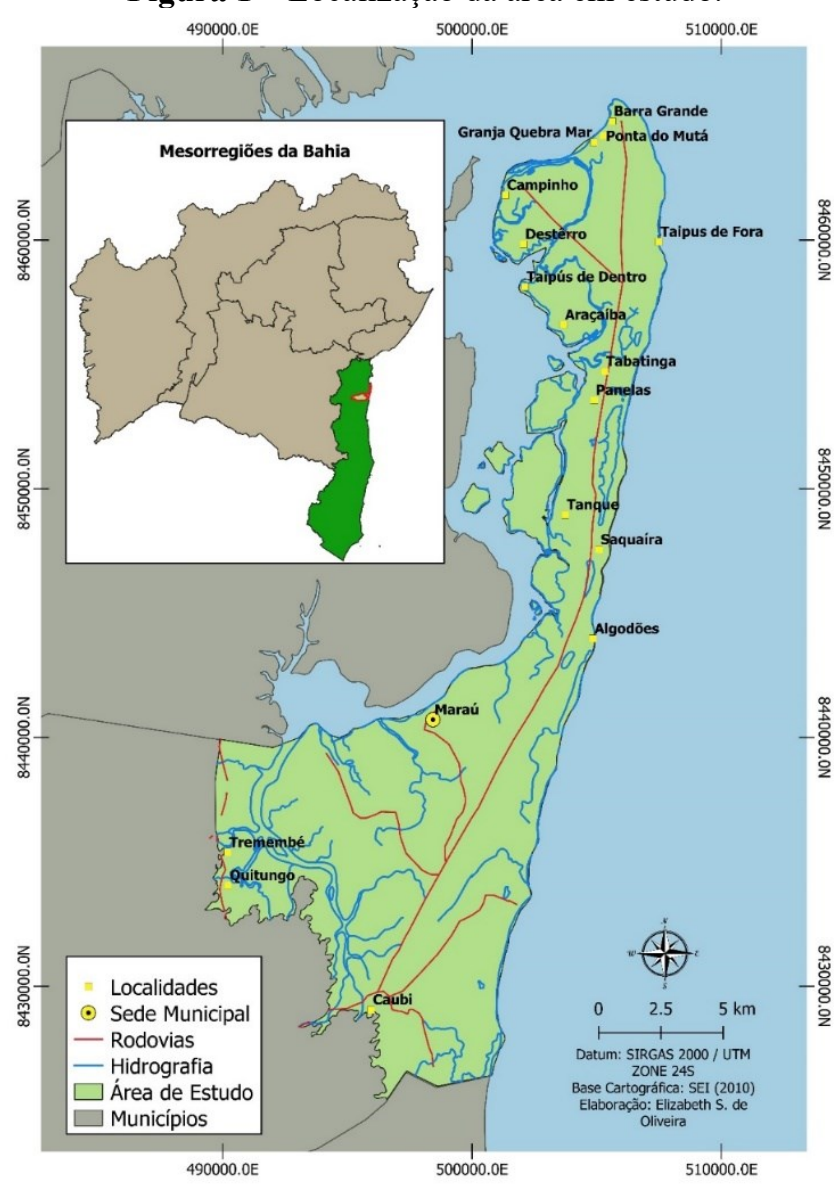

Fonte: Elaborada a partir do banco de dados do SEI (2010) e de WALDBURGUER (2014).

A figura 2 apresenta as características litológicas do substrato rochoso da península de Maraú, nota-se que ao longo da península ocorre predominantemente substratos arenosos associados aos terraços marinhos holocênicos e pleistocênicos, depósitos arenosos de leques aluviais e sedimentos areno-argilosos do Grupo Barreiras. 
Figura 2 - Substrato Rochoso da Área Estudada.

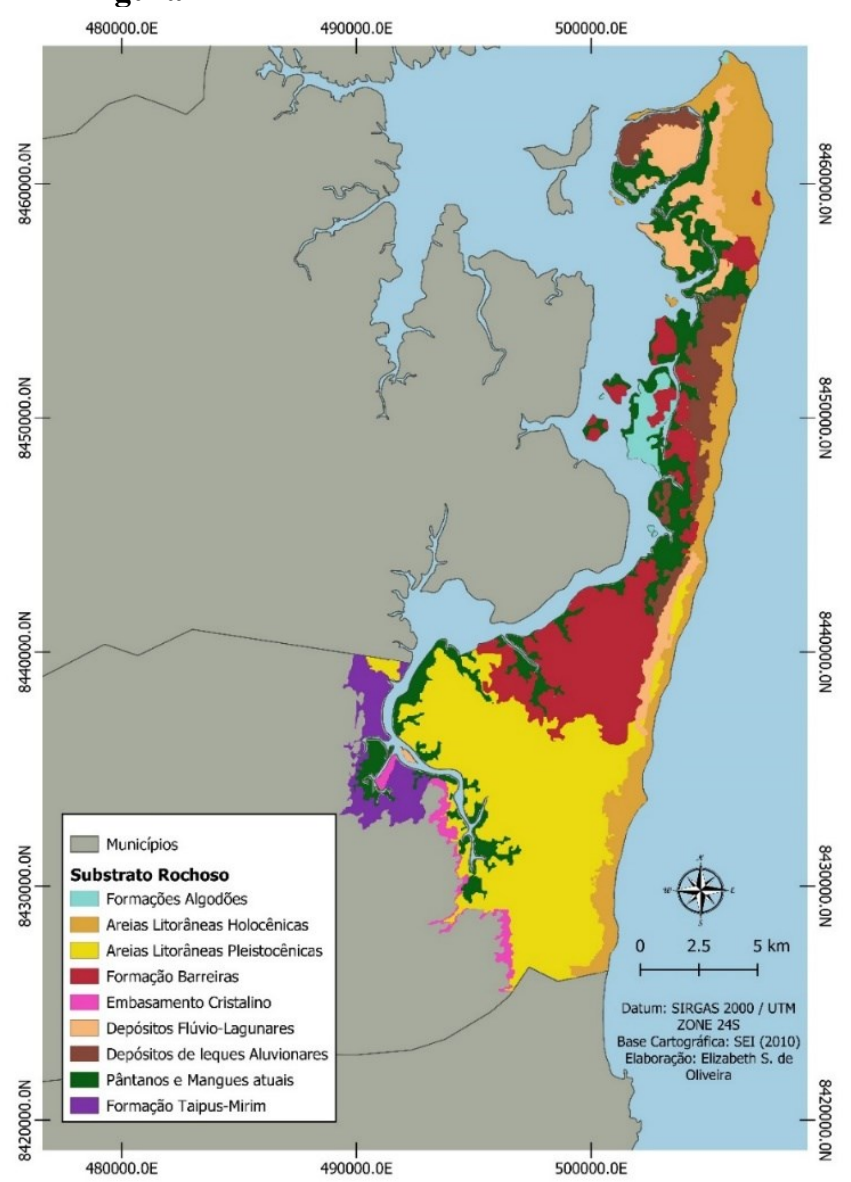

Fonte: Elaborada a partir do banco de WALDBURGUER (2014).

Franco et al. (2011) ao estudarem a fragilidade ambiental da bacia hidrográfica do rio Almada justificaram a atribuição dos pesos para cada unidade de substrato rochoso a partir do grau de coesão, pois este determina a resistência das rochas, logo, representa a intensidade da ligação entre os minerais e partículas que as constituem. Dessa forma, litologias mais antigas do embasamento cristalino apresentam menor grau de fragilidade, enquanto que os sedimentos do grupo barreiras e a formação taipus-mirim apresentam grau intermediário. A formação algodões apresentam grau de fragilidade elevado, assim como os sedimentos inconsolidados do Quaternário e os Pântanos e Mangues, que receberam o valor máximo (tabela 2).

As classes de declividade foram estabelecidas de acordo com o estudo de Waldburguer e Gomes (2016), estão descritas na tabela 3 e apresentadas na figura 3. 
Tabela 3 - Características das classes de declividade da área estudada.

\begin{tabular}{|c|c|}
\hline Classes de Declividade (\%) & Descrição \\
\hline$<6$ & $\begin{array}{l}\text { Relevo plano associado aos terraços marinhos quaternários, praias e } \\
\text { depósitos de mangues atuais. }\end{array}$ \\
\hline $6-12$ & $\begin{array}{l}\text { Relevo associado à ocorrência de feições tipo cordões litorâneos } \\
\text { inseridos nos terraços marinhos. }\end{array}$ \\
\hline $12-20$ & $\begin{array}{l}\text { Relevo de morros e colinas associado ao substrato do Grupo Barreiras e } \\
\text { dos sedimentos mesozóicos da Bacia de Camamu. }\end{array}$ \\
\hline $20-30$ & $\begin{array}{l}\text { Relevo de morros e colinas associado ao substrato do Grupo Barreiras e } \\
\text { dos sedimentos mesozóicos da Bacia de Camamu. }\end{array}$ \\
\hline$>30$ & $\begin{array}{l}\text { Relevo íngreme associado a encostas do embasamento cristalino e do } \\
\text { Grupo Barreiras. }\end{array}$ \\
\hline
\end{tabular}

Fonte: Adaptado de Waldburguer e Gomes (2016).

Imagem 3 - Declividade da área estudada.

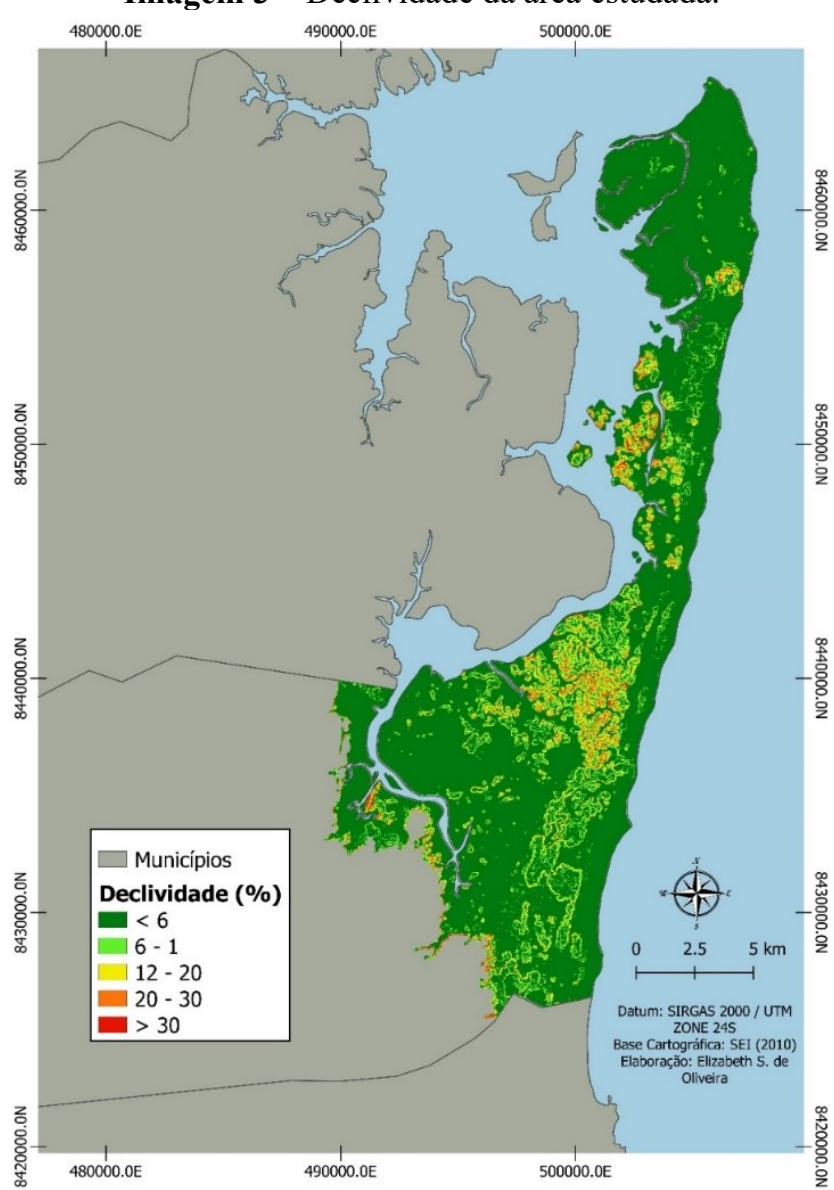

Fonte: Elaborada pelos próprios autores (2020).

A resistência do solo aos processos erosivos se dá a partir de suas características, tais como textura, porosidade, permeabilidade, aderência, estrutura e profundidade. Essas características que irão definir a susceptibilidade do solo em resistir aos processos erosivos, por isso é importante analisalos no estudo de fragilidade ambiental (FRANCO et al. 2010). 
Foi utilizado o mapa de solos adaptado por Waldburguer (2014) para a zona costeira de Maraú e Camamu, e a atribuição dos valores de fragilidade se deu de acordo com as características de cada tipo. A tabela 4 a seguir apresenta as características dos solos presentes na Península de Maraú (Figura 4).

Tabela 4 - Características das classes de solo da área estudada.

\begin{tabular}{|c|c|}
\hline Classes de Solos & Descrição \\
\hline Gleissolos & $\begin{array}{l}\text { Associados ao substrato de pântanos e mangues atuais, desenvolvem-se } \\
\text { em áreas alagadiças em lençol freático raso e topografia plana. }\end{array}$ \\
\hline Espodossolos & $\begin{array}{l}\text { Distribuídos em áreas dos depósitos arenosos flúvio-lagunares, terraços } \\
\text { arenosos e depósitos de leques aluviais. São caracterizados pela presença } \\
\text { de horizonte espódico, constituído pela concentração de matéria } \\
\text { orgânica. }\end{array}$ \\
\hline Neossolo Quartzarênico & $\begin{array}{l}\text { Associados aos terraços arenosos caracterizados pela presença de areia } \\
\text { ao longo de pelo menos } 2 \mathrm{~m} \text { de profundidade. São constituídos } \\
\text { essencialmente de grãos de quartzo. }\end{array}$ \\
\hline Argissolo Vermelho-Amarelo distrófico & $\begin{array}{l}\text { Ocorrem em áreas onde afloram os sedimentos inconsolidados do Grupo } \\
\text { Barreiras. São caracterizados por solos profundos a pouco profundos, } \\
\text { bem drenados, de textura arenosa. }\end{array}$ \\
\hline Latossolo Amarelo distrófico & $\begin{array}{l}\text { Associados ao substrato dos sendimentos mesozoicos, caracterizados de } \\
\text { rochas intermediárias e básicas, fértil e com boa retenção de água. }\end{array}$ \\
\hline Latossolo Vermelho-Amarelo distrófico & $\begin{array}{l}\text { Ocorrem em áreas onde afloram as rochas do Complexo Cristalino. São } \\
\text { solos bem drenados, profundos, com predominância de textura média e } \\
\text { pouca diferenciação entre os horizontes. }\end{array}$ \\
\hline
\end{tabular}

Fonte: Adaptado de Waldburguer e Gomes (2016). 


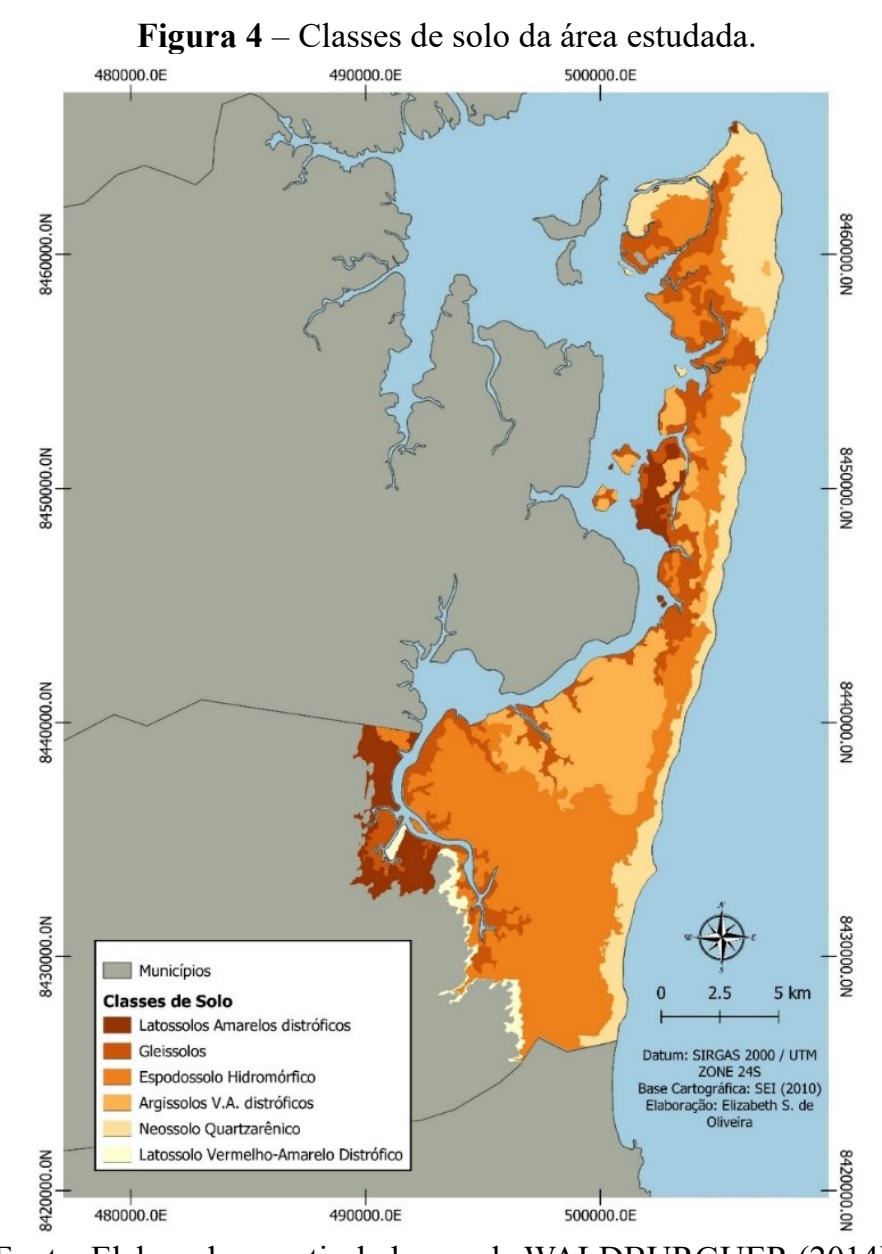

Fonte: Elaborada a partir do banco de WALDBURGUER (2014).

O índice de cobertura vegetal é uma importante variável na análise da fragilidade ambiental, pois a cobertura vegetal tem o papel de proteger a paisagem, sua densidade está relacionada com a capacidade de frear o desencadeamento de processos mecânicos da morfogênese (FRANCO et al., 2011). Foi utilizado o NDVI como variável representativa do vigor da vegetação (figura 5), assim como o uso do solo atual da Península de Maraú (figura 6). 
Figura 5 - Vigor da vegetação (NDVI) da área estudada.

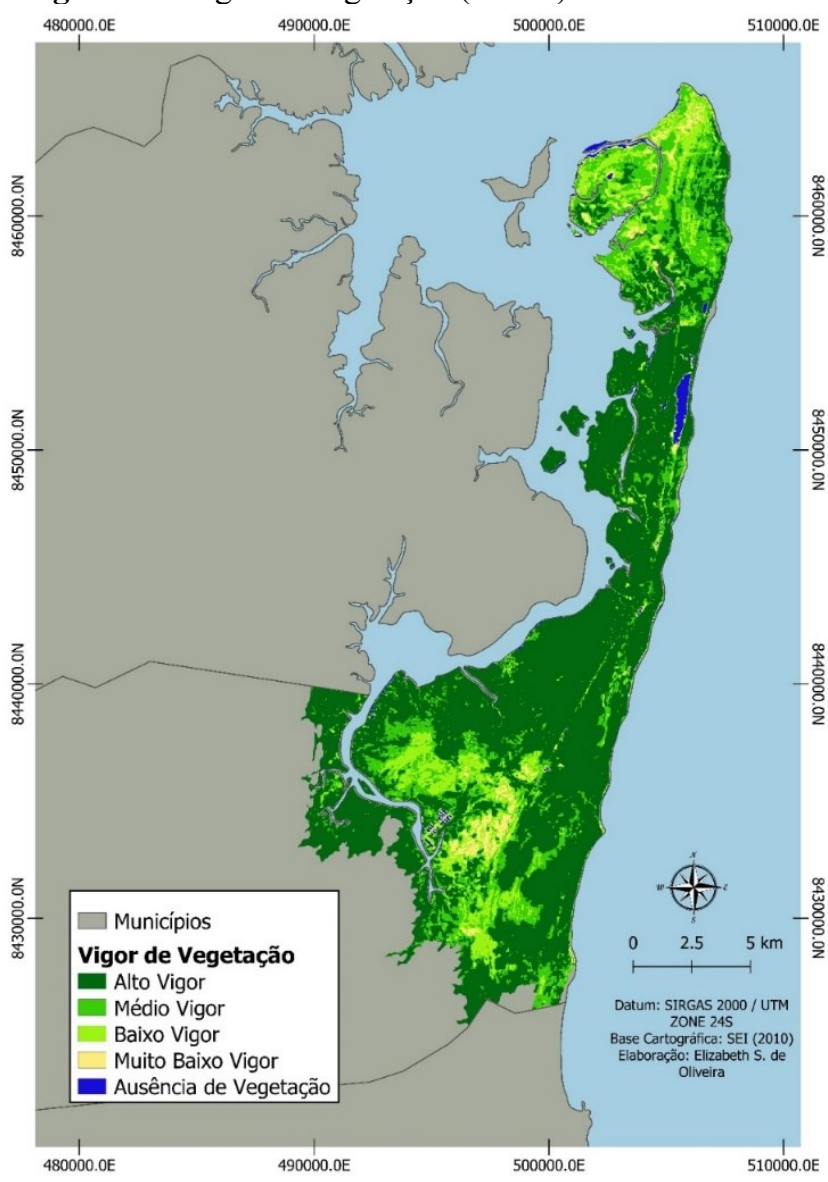

Fonte: Elaborada pelos próprios autores(2020).

O uso e ocupação atual da península de Maraú apresenta a diversidade ecossistêmica de ambiente costeiro, com áreas de manguezais $(11,84 \%)$ distribuídas por toda a península e associadas a rede de drenagem local, sendo que estas recebem influência das marés (WALDBURGUER; GOMES, 2016). As áreas de restingas $(22,95 \%)$ e campos de restinga $(20,43 \%)$ foram as classes mais predominantes do estudo, Waldburguer e Gomes (2016) associaram as restingas aos substratos do terraço arenoso pleistocênico, enquanto que as áreas de Floresta Ombrófila Densa, classificada nesse estudo como Floresta/SAF (18,22\%), foram relacionadas ao relevo e substrato de áreas mais elevadas do embasamento cristalino e de áreas da formação do Grupo Barreiras. 
Figura 6 - Uso e ocupação do solo da área estudada.

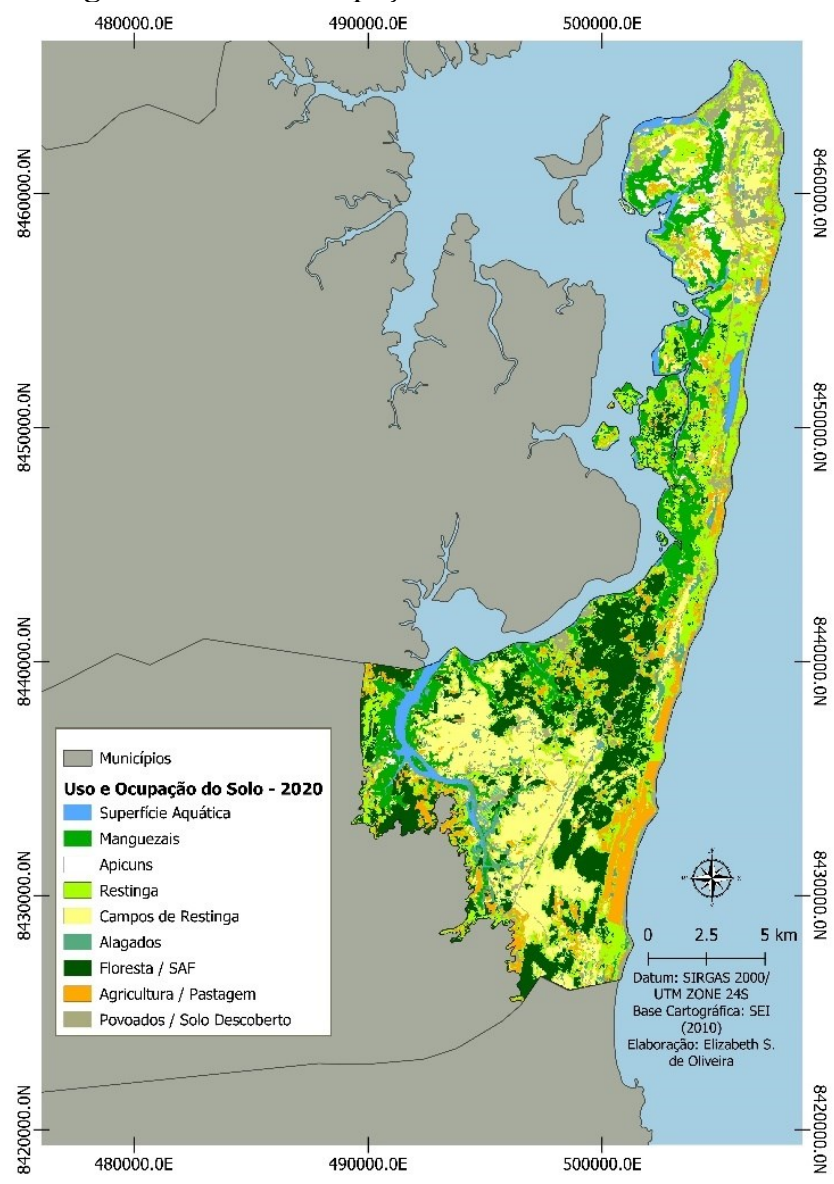

Fonte: Elaborada pelos próprios autores(2020).

As classes Agricultura/Pastagem (9,86\%) e Povoados/Solo Descoberto (7,39\%), são importantes para o estudo da fragilidade ambiental, pois representam a influência antrópica na área estudada. A tabela 5 apresenta os dados de área $\left(\mathrm{Km}^{2} \mathrm{e} \%\right)$ para cada classe encontrada nesse estudo.

Tabela 5 - Quantificação $\left(\mathrm{Km}^{2}\right.$ e \%) das classes de uso e ocupação do solo da área estudada para o ano de 2020.

\begin{tabular}{c|c|c}
\hline \multirow{2}{*}{ Classes } & \multicolumn{2}{|c}{ Área } \\
\cline { 2 - 3 } & $\mathbf{K m}^{\mathbf{2}}$ & $\mathbf{\%}$ \\
\hline Superfície Aquática & 9,9558 & 4,10 \\
\hline Manguezais & 28,71 & 11,84 \\
\hline Apicuns & 3,3543 & 2,38 \\
\hline Restinga & 55,6578 & 20,43 \\
\hline Campo de Restinga & 49,5486 & 3,83 \\
\hline Alagados & 9,2853 & 18,22 \\
\hline Floresta & 44,1954 & 9,86 \\
\hline Agricultura/Pastagem & 23,9175 & 7,39 \\
\hline Povoados/Solo Descoberto & 17,9163 & 100 \\
\hline Total & 242,5410 & \\
\hline
\end{tabular}

Fonte: Elaborado pelos autores (2020). 


\section{RESULTADOS E DISCUSSÃO}

\section{Fragilidade Natural}

A análise da fragilidade natural estabeleceu-se a partir do cruzamento dos atributos: substrato rochoso, declividade, clima e solos. A figura 7 apresenta o Mapa de Fragilidade Natural, as classes encontradas para a área estudada foram: média, alta e muito alta, sendo que $76 \%$ da área estudada foi classificada como muito alta fragilidade natural e $23 \%$ como média (tabela 6).

Figura 7 - Fragilidade Natural da área estudada.

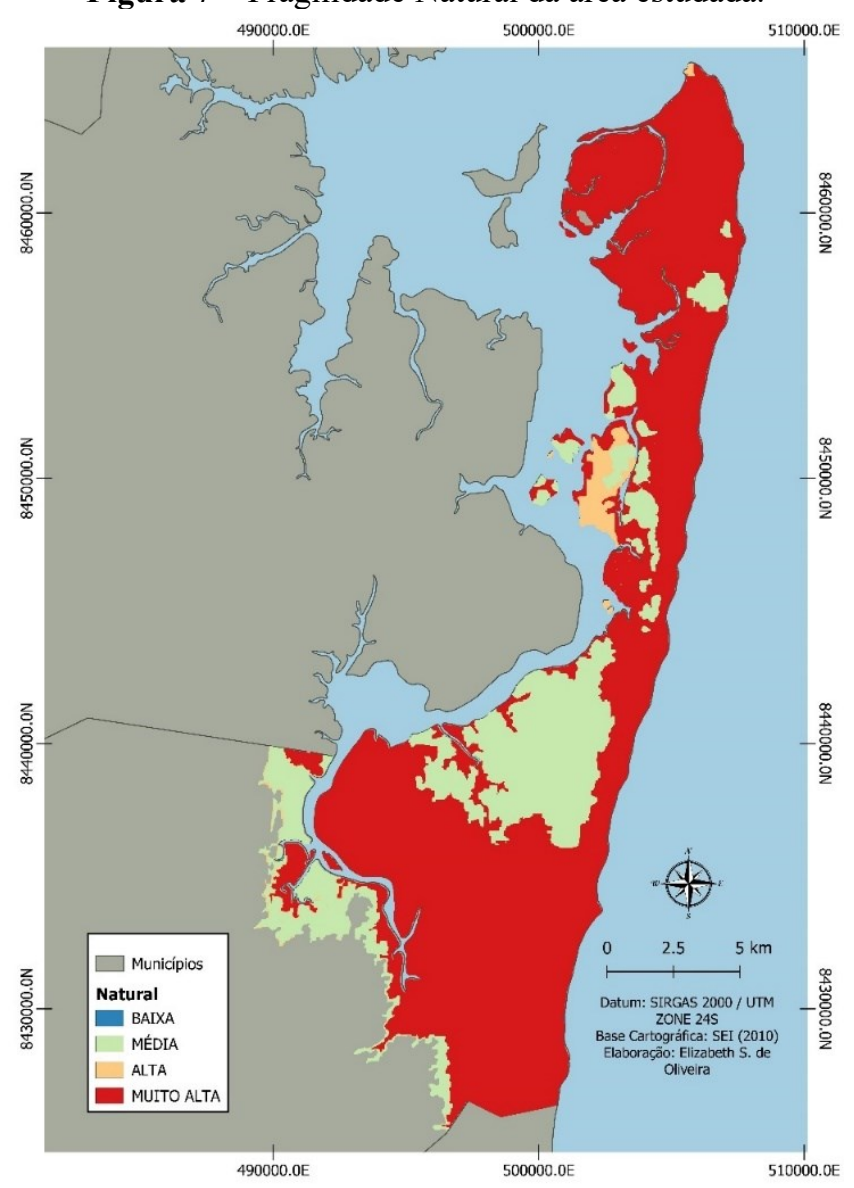

Fonte: Elaborada pelos próprios autores (2020).

Tabela 6 - Distribuição percentual das classes de fragilidade natural da área estudada. Graus de Fragilidade Natural Porcentagem (\%)

\begin{tabular}{c|c}
\hline Baixa & - \\
\hline Média & $23 \%$ \\
\hline Alta & $2 \%$ \\
\hline Muito Alta & $76 \%$ \\
\hline Total & $100 \%$ \\
\hline
\end{tabular}

Fonte: Elaborada pelos autores (2020). 
Ao analisar a figura 7 é possível notar que a área classificada como muito alta fragilidade natural está associada aos cordões litorâneos e manguezais, assim como foi identificado no estudo de Waldburguer e Gomes (2016), o atributo "solos” teve grande representatividade nessa classificação. As áreas de média fragilidade estão relacionadas com os substratos rochosos do Grupo Barreiras, Formação Taipus-Mirim e Embasamento Cristalino.

Os atributos declividade e clima não são muito representativos para a área estudada, pois é uma área pequena que se encontra totalmente em zona costeira, não apresenta variação acentuada em sua declividade, seu o clima é tropical quente e úmido com chuvas bem distribuídas por toda a península. Dessa forma, os atributos que mais contribuem para a fragilidade natural da Península de Maraú são: solos e substratos rochosos.

\section{Fragilidade Ambiental}

Para analisar a fragilidade ambiental além de considerar os atributos do meio físico acrescentou-se o grau de fragilidade do atributo uso e ocupação do solo e do vigor de vegetação (NDVI), dessa forma é possível identificar como as atividades antrópicas estão interagindo sobre o meio natural e quais as suas consequências. A figura 8 apresenta o mapeamento das classes encontradas, que foram: baixa, média, alta e muito alta. 


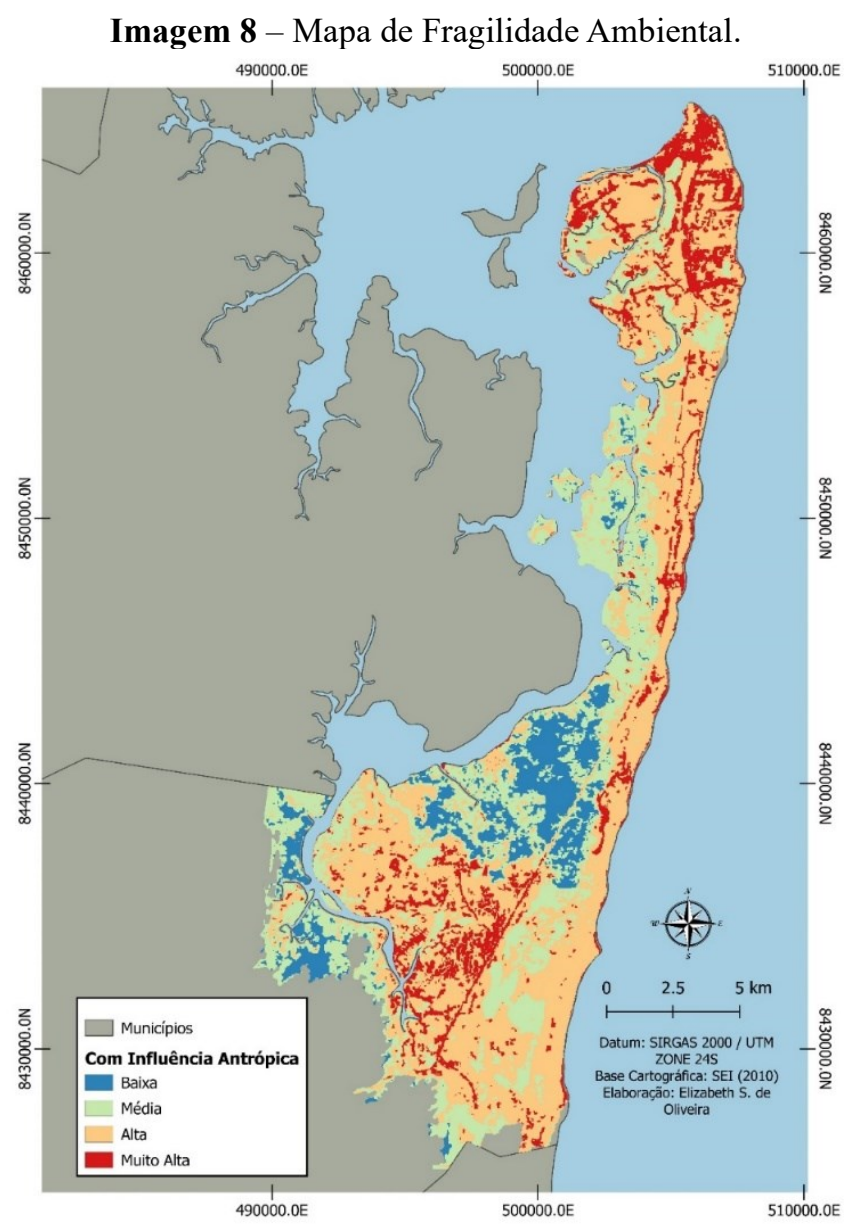

Fonte: Elaborada pelos próprios autores (2020).

Comparado os resultados encontrados (tabelas 6 e 7), podemos notar que apesar do atributo uso e ocupação do solo possuir maior influência no mapeamento (44\%), podemos afirmar que a alta fragilidade ambiental está associada com a fragilidade natural da península (imagem 7). A classe alta fragilidade ocupa $47 \%$ da área estudada e possui maior abrangência, seguida da classe média fragilidade com $30 \%$ (tabela 7 ).

A diminuição da classe "muito alta" se dá em virtude das tipologias de uso e ocupação do solo e do vigor de vegetação, pois a área estudada possui extensa cobertura vegetal natural (restinga, florestas e manguezais). Podemos associar as áreas que apresentaram muito alta fragilidade ambiental com as tipologias Povoados/Solo Descoberto e Alagados. Já o aumento da classe baixa ocorreu em locais ocupados por bolsões florestais preservados em áreas de média fragilidade natural (figura 7).

De forma geral, podemos afirmar que o conhecimento sobre os aspectos físicos é essencial para o planejamento do uso e ocupação de um ambiente, pois a partir dessas atividades pode-se potencializar ou minimizar processos erosivos (BENAVIDES SILVA; MACHADO, 2014). Os resultados encontrados nesse estudo demonstram que a Península de Maraú apresenta muito alta 
fragilidade natural, e a proteção de sua cobertura vegetal natural é essencial para a manutenção da biodiversidade ecológica presente nesse ambiente.

Tabela 7 - Distribuição percentual das classes de fragilidade ambiental.

\begin{tabular}{c|c}
\hline Graus de Fragilidade Natural & Porcentagem (\%) \\
\hline Baixa & $10 \%$ \\
\hline Média & $30 \%$ \\
\hline Alta & $47 \%$ \\
\hline Muito Alta & $13 \%$ \\
\hline Total & $100 \%$ \\
\hline
\end{tabular}

Fonte: Elaborada pelos autores (2020).

\section{CONCLUSÃO}

O diagnóstico ambiental é imprescindível para a gestão do uso e ocupação do solo, pois a partir da identificação da fragilidade natural e ambiental é possível identificar limitações e potencialidades de determinado local. A península de Maraú por ser um ambiente costeiro está susceptível a vários fatores naturais que ocasionam erosão, como o geológico, climático, oceanográfico e biótico. Ambientes costeiros também são mais susceptíveis às transformações socioeconômicas, pois geralmente o turismo é a principal atividade econômica desses locais, e, consequentemente, ocorre transformações no uso e ocupação do solo.

Nesse estudo foi possível verificar que a Península de Maraú possui muito alta fragilidade natural em $76 \%$ da área estudada e média fragilidade natural em $23 \%$, ocasionada principalmente pelos atributos solos e substratos rochosos. Entretanto, quando a influência antrópica foi considerada verificou-se que a fragilidade ambiental foi classificada principalmente como alta (47\% da área) e média (30\% da área), pois a cobertura vegetal natural (restinga, floresta e manguezais) acarretou na diminuição da classe de fragilidade muito alta. Tendo em vista que as áreas classificadas como substrato de areias litorâneas e terraços marinhos apresentaram muito alta fragilidade natural é imprescindível a proteção das restingas associadas a esses substratos, pois estas atuam como amenizadores dos processos erosivos, bem como as outras classes de cobertura natural.

Vale ressaltar que o estudo preliminar de cada atributo considerado é essencial para a atribuição dos pesos de influência na análise de multicritério, pois deve-se considerar todas as peculiaridades individuais da área estudada, sendo necessário realizar pesquisas de campo para verificação das informações levantas. Também é importante destacar que o estudo de fragilidade ambiental exprime a realidade atual, pois é considerado o uso e ocupação do solo atual, logo, esse diagnóstico deve ser atualizado em anos consecutivos para a manutenção dos dados e monitoramento ambiental. 


\section{REFERÊNCIAS}

AHP - Analytic Hierarchy Process. AHP Priority Calculator. Disponível em: https://bpmsg.com/ahp/ahp-calc.php. Acesso em: 18 de agosto de 2020.

ASF - Alaska Satellite Facility. Data Search Vertex. Disponível em: https://vertex.daac.asf.alaska.edu/. Acesso em: 24 de abril de 2020.

BAHIATURSA/ Instituto Ecotema. Zoneamento Ambiental e Diretrizes de Uso: Convênio no . 025/99, Relatório Final. Maraú - Ba, p. 311, 2000.

BENAVIDES SILVA, V. C., MACHADO, P. S. SIG na Análise Ambiental: Susceptibilidade Erosiva da Bacia Hidrográfica do Córrego do Mutuca, Nova Lima - MG. Revista de Geografia (UFPE), v. 31, n. 2, p. 66-87, 2014.

CREPANI, E; MEDEIROS, J.S.; AZEVEDO, L.G.; DUARTE, V.; HERNANDEZ, P.; FLOREnZANo, T. Curso de Sensoriamento Remoto Aplicado ao Zoneamento Ecológico Econômico. São José dos Campos: INPE, 1996.

CLIMATE-DATA. Clima: Maraú, Bahia, Brasil. Disponível em: https://pt.climate-data.org/americadosul/brasil/bahia/marau-43335/. Acesso em: 10 de janeiro de 2021.

DERMACHI, J. C.; PIROLI, E. L.; ZIMBACK, C. R. L. Análise temporal do uso do solo e comparação entre os índices de vegetação NDVI e SAVI no município de Santa Cruz do Rio Pardo - SP usando imagens Landsat-5. RA'E GA - O Espaco Geografico em Analise, n. 21, p. 234-271, 2011. Disponível em: http://hdl.handle.net/11449/73073. Acesso em: 19 de agosto de 2021.

FRANCO, G. B.; MARQUES, E. A. G.; GOMES, R. L.; CHAGAS, C. S.; SOUZA, C. M. P.; BETIM, L. S. Fragilidade Ambiental da Bacia Hidrográfica do Rio Almada - Bahia. Revista de Geografia (UFPE), v. 28, n. 2, 2011.

GEE - Google Earth Engine. Disponível em: https://earthengine.google.com/. Acesso em: 10 de julho de 2020 .

GRIGIO, A.M. Aplicação de Sensoriamento Remoto e Sistema de Informação Geográfica na Determinação da Vulnerabilidade Natural e Ambiental do Município de Guamaré (Rn): Simulação De Risco Às Atividades Da Indústria Petrolífera. Programa de Pós-graduação em Geodinâmica, Universidade Federal do Rio Grande do Norte, Dissertação de Mestrado, p. 222, 2003.

GRIGIO, A.M.; SOUTO, M.V.S.; CASTRO, A.F.; AMARO, V.E.; VITAL, H. \& DIODATO, M.A. Use of remote sensing and geographical information system in the determination of the natural and environmental vulnerability of the Municipal District of Guamaré - Rio Grande do Norte - Northeast of Brazil. Journal of Coastal Research, p. 1427-1431, 2004.

GRIGIO, A.M. Evolução da Paisagem do Baixo Curso do Rio Piranhas-Assu (1988- 2024): Uso de Autômatos Celulares em Modelo Dinâmico Espacial Para Simulação de Cenários Futuros. Programa de Pós-graduação em Geodinâmica, Universidade Federal do Rio Grande do Norte, Tese de Doutorado, p. 217, 2008. 
INPE - Instituto Nacional de Pesquisas Espaciais. Catálogo de Imagens. Disponível em: http://www.dgi.inpe.br/catalogo/. Acessado em: 24 de abril de 2020.

KÖPPEN, W. Das geographische System der Klimate. Gebr, Borntraeger, p. 1- 44, 1936.

LIMA, E. Q.; AMARAL, R. F. Vulnerabilidade da Zona Costeira de Pititinga/RN, Brasil. Mercator, Fortaleza, v. 12, n. 28, p. 141-153, 2013. https://doi.org/10.4215/RM2013.1228.0010

MORIMOTO, R. M.; OLIVEIRA, F. H. Análise do espaço construído a rede de educação infantil utilizando os métodos AHP e SIG: estudo de caso em Camboriú (SC). ArquiteturaRevista, v.15, n.1, 2019.

MOURA, A.C. M. Reflexões metodológicas como subsídio para estudos ambientais baseados em Análise de Multicritérios. Anais XIII Simpósio Brasileiro de Sensoriamento Remoto, Florianópolis, Brasil, INPE, p. 2899-2906, 21-26 abril 2007.

ROSS, J. L. S. Análise empírica da fragilidade dos ambientes naturais e antropizados. Revista do Departamento de Geografia. n.8, p. 63-74, 1994. https://doi.org/10.7154/RDG.1994.0008.0006

SEI - Superintendência de Estudos Econômicos e Sociais da Bahia. Geoinformação. Disponível em: https://www.sei.ba.gov.br/index.php?option=com_content\&view=article\&id=3295\&Itemid=941. Acessado em: 03 de novembro de 2020 .

SAATY, T. The analytic hierarchy process. New York: McGraw-Hill, p. 287, 1980.

TAGLIANI, C.R.A. Técnica para avaliação da vulnerabilidade ambiental de ambientes costeiros utilizando um sistema geográfico de informação. In: Seminário Brasileiro de Sensoriamento Remoto, 11, 2003, Belo Horizonte. Anais, São José dos Campos, INPE, p. 1657-1664, 2003.

VOOGD, H. Multicriteria evaluation for urban and regional planning. London: Pion, p. 370, 1983.

Waldburger, T. C. M. Mapeamento Geoambiental da Zona Costeira dos Municípios de Maraú e Camamu - BA. 2014. p. 60. Dissertação - Mestrado em Desenvolvimento Regional e Meio Ambiente, Universidade Estadual de Santa Cruz, 2014.

WALDBURGER, T. C. M.; GOMES, R. L. Mapeamento Geoambiental da Zona Costeira dos Municípios de Maraú e Camamu - BA. Revista de Geografia (Recife), vol. 33, n. 3, 2016. Disponível em: https://periodicos.ufpe.br/revistas/revistageografia/issue/view/RG\%2033\%2C3. Acessado em: 03 de novembro de 2020. 